\title{
Prevalence and determinants of differences in cystatin $C$ and creatinine-based estimated glomerular filtration rate in community-dwelling older adults: a cross-sectional study
}

\author{
Helen Legrand ${ }^{1 *}$ (D, Karin Werner ${ }^{1,2}$, Anders Christensson ${ }^{3,4,5}$, Mats Pihlsgård ${ }^{1,2}$ and Sölve Elmståhl1,2
}

\begin{abstract}
Background: Differences in cystatin C and creatinine-based estimated glomerular filtration rate (eGFR) can lead to clinical uncertainty. Existing eGFR equations perform poorly in a subset of individuals. This study aims to describe the prevalence of differences between cystatin C-based (eGFR cys) and creatinine-based (eGFR creat) eGFR in older adults and to explore which subsets of individuals may be most affected by differing estimations.

Methods: In this cross-sectional study, participants from a cohort of community-dwelling older adults were examined at a baseline visit in 2001-2004 as part of the larger "Good Aging in Skåne" study. Exposure variables were obtained from questionnaires, interviews, examinations, and medical records. Blood samples were taken during the baseline visit, cryopreserved, and analyzed at a later time for biomarkers. The CKD-EPI equations were used to estimate GFR. Initial descriptive analyses were performed on 2931 individuals. A total of 2532 participants were included in the final multiple linear regression.

Results: Nearly two-thirds of participants had eGFR differences exceeding 10\%, with nearly $20 \%$ of participants having eGFR differences exceeding 30\%. Smoking, age, body mass index (BMI), C-reactive protein (CRP), glucocorticoid use, and mean eGFR were correlated with differences between eGFR creat and eGFR cys.

Conclusions: Differences between eGFR $R_{\text {creat }}$ and GFF $_{\text {cys }}$ are common and often of large magnitude in this community-dwelling population of older adults. The finding of multiple non-GFR determinants correlated to differences in GFR estimations can help direct future research to improve eGFR equations for subgroups prone to conflicting GFR estimations or to guide choice of biomarker for GFR estimation in these subgroups.
\end{abstract}

Keywords: Cystatin C, Creatinine, Glomerular filtration rate, Older adults, Community-dwelling

\section{Background}

Glomerular filtration rate (GFR) estimating equations based on creatinine and cystatin $\mathrm{C}$ perform well overall but yield different and sometimes contradictory results in a subset of individuals [1-10]. Clinicians are chiefly concerned with the quality of estimated GFR (eGFR) for individual patients for drug dosing, diagnosis of kidney

\footnotetext{
* Correspondence: helen.legrand@med.lu.se

'Department of Clinical Sciences Malmö, Lund University, Jan Waldenströms gata 35, 20502 Malmö, Sweden

Full list of author information is available at the end of the article
}

disease, and follow-up of kidney function. To improve GFR estimation methods at the individual level it is first necessary to understand which, if any, particular subgroups are prone to poor estimation using one or both biomarkers. Biomarker concentrations are affected by GFR and non-GFR determinants, some of which are corrected for in current estimation equations, for example with coefficients for race and sex. Better understanding of affected subgroups could lead to recommendations on which biomarker to favor when choosing an equation for a patient in a particular subgroup, or could lead to 
development of additional correction coefficients for non-GFR determinants of biomarker concentrations. Some recent studies have also indicated that a large difference between cystatin $\mathrm{C}$ based and creatinine based eGFR can be a marker for increased risk for morbidity and mortality [11-13]. The pathophysiology of this association has not been determined although glomerular pore size has been hypothesized to play a role. Knowledge of which groups may be more prone to large differences in GFR estimates may give insight into this phenomenon.

Most previous studies have focused on determining which eGFR equation is optimal compared to a gold standard. Several studies have examined factors other than GFR affecting creatinine or cystatin C [14-33]. Few have looked specifically at factors affecting consistency between different eGFR equations [34-38].

The first objective of this study is to determine the prevalence and size of differences in GFR estimation using creatinine-based (eGFR creat) or cystatin C-based $\left(e G F R_{\text {cys }}\right.$ ) equations in a community-dwelling population of older adults. The main objective of the study is to explore correlations between non-GFR determinants of biomarkers and differences in eGFR with the aim of finding subgroups for further study.

\section{Methods}

\section{Population}

We used a cross-sectional analysis of the longitudinal cohort study Good Aging in Skåne (GÅS) to study the prevalence and size of eGFR differences as well as their association with selected non-GFR determinants (exposure variables). GÅS is a longitudinal cohort study with an initial baseline population of 2931 individuals 60 to 93 years of age, recruited from nine age cohorts $(60,66$, $72,78,81,84,87,90$, and 93+) from five rural and urban municipalities in southern Sweden. Selection was at random on the basis of the National population register. Oversampling was used in older age groups for better power. Participants were invited by letter with telephone follow-up, with continuous recruitment to reach a goal of 3000 participants. Eligibility criteria were the ability to speak and understand Swedish and to still be living within the study area at time of recruitment. Baseline study visits began January 8, 2001 and ended July 30, 2004. Visits took place at one of the study clinics or at the place of residence if the participant was unable to come to a study clinic.

\section{Variables}

The outcome variable in both components of the analysis was the difference obtained by substracting eGFRcreat from eGFR ${ }_{\text {cys }}$, divided by the mean value of the two equation results. The resulting values were positive or negative percentages. The eGFR equations used are from the CKD-EPI collaboration [10]. Although they were not developed in elderly populations, the CKD-EPI equations were chosen because they include both eGFR $_{\text {creat }}$ and GFR $_{\text {cys }}$ and have been validated in multiple elderly populations, including in a subset of the current study population [9, 39-42]. Ethnicity was not recorded in this study. Due to the preponderance of participants of European ancestry in this cohort the equations were calculated under the assumption that all participants were of European ancestry.

In the descriptive part of the analysis the outcome variable was collapsed into categories of size of difference in eGFR $(<10 \%, 10-30 \%,>30 \%)$. These categories were chosen based on the commonly-used cut-off points for describing the accuracy of GFR estimating equations [43]. Prevalence of each category was calculated for the categories of age by decades, sex, and mean eGFR based on the average of eGFR $\mathrm{creat}_{\text {ch }}$ and eGFR $\mathrm{R}_{\text {cys. }}$.

Multiple factors appearing to affect serum concentration of creatinine and cystatin $\mathrm{C}$ have previously been reported [14-33, 44-47]. The most well-described of these were included in the second part of the analysis. The exposure variables tested were age, sex, smoking, hypertension, BMI, diabetes, thyroid function, glucocorticoid use, CRP level, and mean eGFR. Data on these variables were collected at baseline visits to the study clinic during examination by a registered nurse and a physician, including consultation of participant medical records, and by participant self-report through interviews and questionnaires. Cystatin $C$ and creatinine were analyzed based on plasma samples taken from participants at the baseline study visit and subsequently cryopreserved to be analyzed as one batch at a later time. Details of variable collection methods can be found in Additional file 1.

\section{Statistical analysis}

For the main part of the analysis multiple linear regression was performed using the General Linear Model procedure in SPSS (Version 22.0. Armonk, NY: IBM Corp.). The exposure variables thyroid status (hypothyroid or hyperthyroid relative to euthyroid), smoking status (current or former smoker relative to non-smoker), sex (male relative to female), hypertension, diabetes, glucocorticoid use, age, BMI, CRP, and mean eGFR (all detailed in Additional file 1) were simultaneously entered into the equation. Cases with missing data points were excluded listwise. Testing of model assumptions was performed with Q-Q plotting and plotting of standardized residuals by predicted values.

\section{Results}

The final multiple linear regression analysis included 2532 individuals. Participant flow is detailed in Fig. 1. 


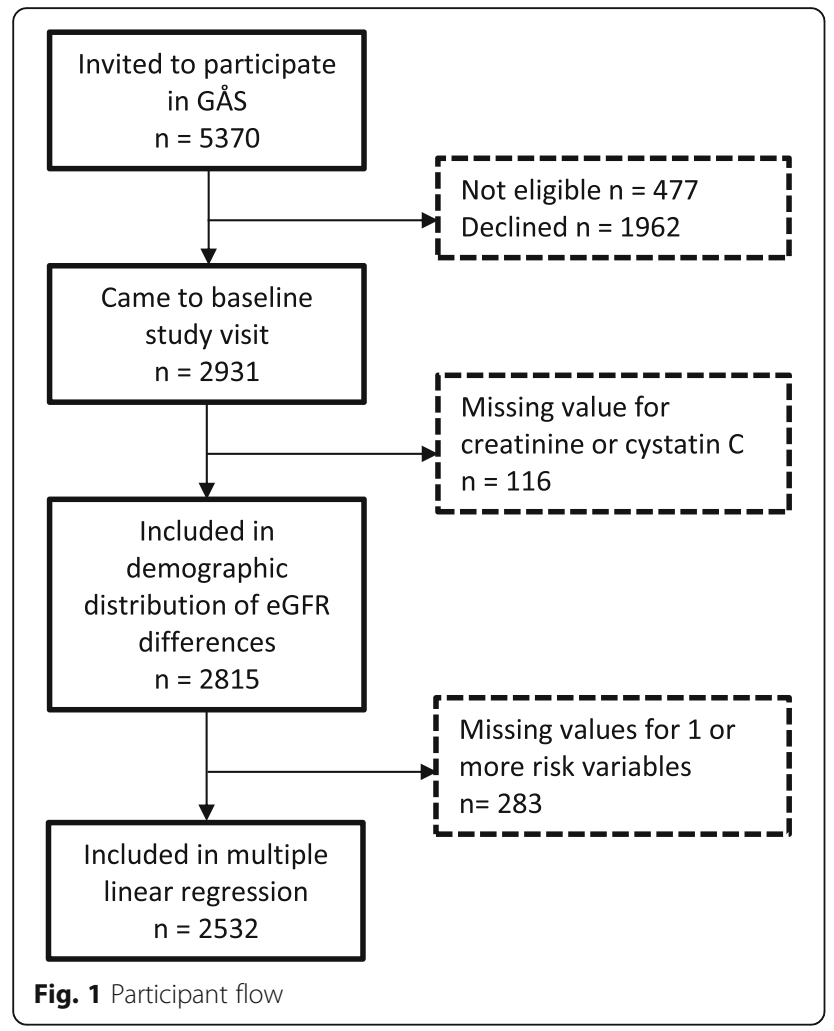

Descriptive data on the prevalence of the exposure variables studied is detailed in Table 1 .

\section{Main results}

Results of the preliminary descriptive study of the prevalence and size of differences in eGFR in this population are presented in Table 2. The mean age of the population was 73.1 years (SD 11) and the mean eGFR was 66 (SD 19). Of note, 526 individuals (19\%) had a greater than $30 \%$ difference between eGFR $\mathrm{R}_{\text {creat }}$ and $\mathrm{GFF}_{\text {cys. }}$. The descriptive study also showed a trend towards increasing differences between GFR estimates with increasing age and with decreasing mean eGFR. The mean difference was $-1,5 \mathrm{ml} / \mathrm{min} / 1.73 \mathrm{~m}^{2}$ (SD 15) indicating generally higher eGFR creat $_{\text {than }}$ eGFR cys $_{\text {. }}$

The outcome of the multiple linear regression analysis of biomarker determinants on the percent difference in eGFR is detailed with confidence intervals in Table 3. Current smoking (relative to never smoking) and glucocorticoid use were associated with 10 and 9 percentage points greater difference between eGFR values, respectively (former smoking did not differ significantly from never smoking). Each year of increasing age, unit of increased BMI, and $\mathrm{mg} / \mathrm{L}$ of increased CRP were associated with $1,0.3$ and 0.3 percentage points of greater difference in estimated eGFR, respectively. An increase in mean eGFR was associated with a higher $\mathrm{GGFR}_{\mathrm{cys}}$, $(0,2$ percentage points greater difference per $\mathrm{mL} / \mathrm{min} /$
Table 1 Distribution of exposure variables in the study population $(n=2931)$

\begin{tabular}{|c|c|c|}
\hline \multicolumn{3}{|l|}{ Categorical variables } \\
\hline & n (\%) & $\mathrm{n}$ missing (\%) \\
\hline Thyroid function & & $38(1.3)$ \\
\hline Hypothyroid & $171(5.8)$ & \\
\hline Hyperthyroid & $88(3.0)$ & \\
\hline Euthyroid & $2634(90)$ & \\
\hline Smoking & & $114(3.9)$ \\
\hline Current & $474(16)$ & \\
\hline Former & $1067(36)$ & \\
\hline Never & $1276(44)$ & \\
\hline $\operatorname{Sex}^{\mathrm{a}}$ & & - \\
\hline Male & $1295(44)$ & \\
\hline Female & $1636(56)$ & \\
\hline Treated for hypertension & 849 (29) & $26(0.9)$ \\
\hline Diabetes & $229(7.8)$ & $16(0.5)$ \\
\hline Glucocorticoid use $e^{a}$ & $104(3.5)$ & - \\
\hline \multicolumn{3}{|l|}{ Continuous variables } \\
\hline & mean (SD) & $\mathrm{n}$ missing (\%) \\
\hline $\mathrm{Age}^{\mathrm{a}}$ & $73.1(11)$ & - \\
\hline BMI $\left(\mathrm{kg} / \mathrm{m}^{2}\right)$ & $26.8(4.4)$ & $80(2.7)$ \\
\hline CRP (mg/L) & $5.1(10)$ & $180(6.1)$ \\
\hline Mean eGFR $\left(\mathrm{mL} / \mathrm{min} / 1.73 \mathrm{~m}^{2}\right)$ & 66 (19) & $116(4.0)$ \\
\hline
\end{tabular}

${ }^{\mathrm{a} V a r i a b l e s ~ w i t h ~ t h e o r e t i c a l l y ~ c o m p l e t e ~ d a t a ~ a v a i l a b l e ~ f o r ~ a l l ~ p a r t i c i p a n t s ~}$

Table 2 Demographic distribution of absolute percent difference in eGFR, 100× (eGFR cys $\left.-\mathrm{eGFR}_{\text {creat }}\right) /$ mean eGFR $(n=2815)$

\begin{tabular}{llll}
\hline Difference in eGFR & $\begin{array}{l}<10 \% \\
\mathrm{n}(\%)\end{array}$ & $\begin{array}{l}10-30 \% \\
\mathrm{n}(\%)\end{array}$ & $\begin{array}{l}>30 \% \\
\mathrm{n}(\%)\end{array}$ \\
\hline Age & & & \\
$60-69$ & $520(39)$ & $653(49)$ & $165(12)$ \\
$70-79$ & $220(40)$ & $240(45)$ & $79(15)$ \\
$80+$ & $249(27)$ & $407(43)$ & $282(30)$ \\
Sex & & & \\
$\quad$ Male & $437(35)$ & $589(47)$ & $228(18)$ \\
Female & $552(35)$ & $711(46)$ & $298(19)$ \\
$\begin{array}{l}\text { Mean eGFR } \\
\text { (mL/min/1.73 m²) }\end{array}$ & & & \\
$<45$ & $106(26)$ & $165(40)$ & $140(34)$ \\
$45-60$ & $181(30)$ & $267(44)$ & $165(27)$ \\
$>60$ & $702(39)$ & $868(48)$ & $221(12)$ \\
Total & $989(35)$ & $1300(46)$ & $526(19)$ \\
\hline
\end{tabular}


Table 3 Results of multiple linear regression of biomarker determinants on the percent difference in eGFR

\begin{tabular}{lll}
\hline Biomarker determinants & $\begin{array}{l}\text { Unstandardized } \\
\beta \text { coefficient }\end{array}$ & $\begin{array}{l}\text { 95\% Confidence } \\
\text { Interval }\end{array}$ \\
\hline Hypothyroid & 0.16 & $-3.03,3.35$ \\
Hyperthyroid & -0.79 & $-5.02,3.44$ \\
Current smoker & -9.88 & $-12.1,-7.71$ \\
Former smoker & -0.29 & $-1.99,1.41$ \\
Sex & 1.36 & $-0.21,2.93$ \\
Treated for hypertension & 0.56 & $-1.17,2.29$ \\
Diabetes & -0.97 & $-2.95,2.76$ \\
Glucocorticoid use & -8.78 & $-12.9,-4.69$ \\
Age (years) & -0.76 & $-0.87,-0.66$ \\
BMI (kg/m ${ }^{2}$ ) & -0.25 & $-0.42,-0.07$ \\
CRP (mg/L) & -0.29 & $-0.37,-0.21$ \\
Mean eGFR (mL/min/1.73 $\mathrm{m}^{2}$ ) & 0.22 & $0.16,0.28$ \\
\hline
\end{tabular}

Percent difference in eGFR expressed as: 100 times the value of (eGFR cys $_{-}$ eGFR $\left._{\text {creat }}\right) /$ mean eGFR $(n=2532)$

$1.73 \mathrm{~m} 2$ ). Note, however, that this parameter must be interpreted with caution as its statistical significance may well be an artefact of the construction of the outcome. Diabetes, hypo- and hyperthyroidism, sex, and treated hypertension did not seem to affect the difference between eGFR creat $_{\text {and eGFRcys. }}$

\section{Discussion}

This study demonstrates that in a community-dwelling population of older adults, eGFR creat $_{\text {and }} \mathrm{eGFR}_{\text {cys }}$ yield estimates that differ by more than $10 \%$ in nearly twothirds of cases. In nearly $20 \%$ of cases the two estimates differ by more than $30 \%$. Our results show that smoking, age, BMI, CRP and glucocorticoid use are correlated with increasing $e G F R_{\text {creat }}$ or decreased $e G_{F} R_{\text {cys }}$ while mean eGFR displays the inverse correlation.

Although it is not possible from this study to know whether the findings are chiefly attributable to effects on creatinine or cystatin $\mathrm{C}$, these findings are not in conflict with previous research on biomarker determinants [15-18, 21-23, 30, 32, 34, 36, 38, 44]. Hypothetical explanations for the correlations seen in this study include a decrease in serum creatinine due to loss of muscle mass in the case of increasing age, prolonged glucocorticoid use or inflammatory disease; the latter being reflected by increased CRP. There have been numerous hypotheses regarding the influence of non-GFR determinants, including body composition, on cystatin $\mathrm{C}$ but the physiological mechanisms are not as clear as in the relationship between muscle mass and creatinine levels. Results have often been conflicting regarding the extent of influence of lean body mass, adiposity, diabetes, smoking, level of inflammation, and thyroid function on the cystatin $C$ concentration in blood [16, 19-21, 23, 25, $26,28,33,35-37,48]$. In addition to the potential effect of non-GFR determinants on cystatin $\mathrm{C}$ and creatinine production, these biomarkers may also be differentially eliminated in the glomeruli. Previous research has hypothesized the existence of a shrunken pore syndrome, wherein various pathological factors could lead to changes in glomerular membrane pore diameter [11, 49-51]. This could in turn explain differing filtration rates of differentlysized macromolecules, in this case creatinine (113 Da) and cystatin C (13.3 kilodaltons). Recent studies in select adult populations have shown that close to $10 \%$ of patients studied display a ratio of $\mathrm{eGFR}_{\mathrm{cys}}$ to $\mathrm{eGFR}_{\text {creat }}$ less than or equal to 0.6 , which has been defined by researchers as indicative of shrunken pore syndrome [49]. These patients are at generally increased risk for morbidity and mortality, and at higher risk for right ventricular dysfunction and for death after coronary artery bypass grafting [11-13]. It is unknown to what extent the hypothesized shrunken pore syndrome may explain differences in GFR estimates in elderly populations compared to other non-GFR determinants of cystatin $C$ and creatinine that were found to be correlated to differences in eGFR in the current study. The above hypothetical pathophysiological models for the observed differences in GFR estimates can be kept in mind when designing future studies.

The results of this study should prompt clinicians to consider whether one or both biomarkers should be used for GFR estimation in older adults. A clinically important difference between eGFR $\mathrm{Cys}_{\text {ch }}$ and $\mathrm{eGFR}_{\text {creat }}$ is not unusual and should be anticipated when the patient profile includes factors known to affect biomarkers.

A strength of this study is its sampling from a general community-dwelling population of elderly both with and without chronic kidney disease.

Choice of risk variables was based on factors known to affect non-GFR determinants of creatinine and cystatin C. One of the strengths of this study is that most factors known to significantly affect biomarkers are included as variables. However, chiefly for reasons of power, not all potential variables were included. For instance, usage of cimetidine or trimethoprim, which have been associated with changes in creatinine metabolism [24, 45, 47], were not included as the total number of study participants taking one of these medications was only six $(0.2 \%)$.

This study is subject to the common self-selection bias of participants that are healthier on average than the general population of older adults, despite efforts to minimize bias by offering home visits to participants unable to come to the study center. Our assumption is that a healthier population with fewer individuals in the disease-defined biomarker determinant categories decreases the chances of finding correlations between risk variables and the outcome variable. In this age cohort in the study region there are few, if any, non-white 
individuals. This could affect the generalizability of these results. Race was not recorded during the study, so the exact number of non-white participants is not known.

Although efforts were made to decrease misclassification of exposure variables by accessing both medical records and participant self-report, some of the variables may be subject to bias, most notably variables that rely on medical diagnoses. These are the categories of treatment for hypertension, diabetes, and thyroid function. Hypertension, diabetes, and thyroid function are not routinely screened for in Sweden and therefore it is likely that some proportion of participants were undiagnosed, potentially leading to a misclassification bias. It is also important to mark a distinction between the presence of illness and the presence of treated illness. However, generally speaking, in the Swedish healthcare system all patients with diagnosed diabetes, current imbalances in thyroid hormone production or clinically relevant hypertension receive treatment. The above limitations would tend to bias towards unity and may explain why we were unable to find a correlation between these factors and differences in eGFR $\mathrm{Great}_{\text {ch }}$ and eGFR $\mathrm{Gys}_{\text {. }}$.

A factor limiting the scope of our study is the lack of measured GFR, meaning we are limited to exploratory analyses of the correlations between biomarker determinants and inconsistencies in estimated GFR. In addition, our consideration of anthropometrics was limited to the use of BMI. Specific consideration of muscle mass and adiposity in relation to the biomarkers and eGFR would require a more accurate measure of body composition, such as Dual-Energy X-ray Absorptiometry (DEXA).

\section{Conclusions}

Our findings suggest that efforts to improve GFR estimating equations may benefit from including the non-GFR determinants smoking, age, BMI, CRP and glucocorticoid use in future analyses to determine if correction coefficients could improve estimation in subpopulations. Some of the affected subpopulations are large, as exemplified by the $16.2 \%$ of our population who were current smokers, meaning that the clinical impact of adjustments in eGFR could be substantial. Other future studies could focus on subgroup analysis of risk categories to determine whether one biomarker is superior to the other in particular risk groups.

\section{Additional file}

Additional file 1: Variable methods describing the collection method and coding for each study variable. (PDF $102 \mathrm{~kb}$ )

\section{Abbreviations}

BMI: Body mass index; CKD-EPI: Chronic kidney disease epidemiology collaboration; CRP: C-reactive protein; eGFR: Estimated glomerular filtration rate; eGFR creat: Creatinine-based eGFR; eGFR cys: Cystatin C-based eGFR;
GÅS: Good Aging in Skåne; GFR: Glomerular filtration rate; SD: Standard deviation

\section{Acknowledgements}

Our thanks go to the administrative and clinical staff of the GÅs study for their invaluable work, to Ole Larsen for his vital assistance in quality control of the data, and to the study participants who have made this work possible.

\section{Funding}

Funding for GAS is provided by the Swedish Ministry of Health and Social Affairs and the Vårdal Institute. Support was received from The Swedish Kidney Association, Stiftelsen för njursjuka, Skåne University Hospital Research Fund, and the Research and Development Council of Region Skåne, Sweden. Region Skåne and Lund University employed the researchers. The funders had no role in design of the study or collection, analysis, and interpretation of data or in writing the manuscript.

\section{Availability of data and materials}

The data that support the findings of this study are available from the GAS study leaders but restrictions apply to the availability of these data, which were used with permission after application for the current study, and so are not publicly available. Data are however available from the authors upon reasonable request and with permission of the study leaders.

\section{Authors' contributions}

All authors participated in study design and conception. HL performed the statistical analysis and drafted the manuscript. All authors revised and approved the final version of the manuscript.

Ethics approval and consent to participate

The study was approved by the regional ethics committee at Lund University (LU 744-00). All subjects provided written consent to participate.

\section{Consent for publication}

Not applicable.

\section{Competing interests}

The authors declare that they have no competing interests.

\section{Publisher's Note}

Springer Nature remains neutral with regard to jurisdictional claims in published maps and institutional affiliations.

\section{Author details}

'Department of Clinical Sciences Malmö, Lund University, Jan Waldenströms gata 35, 20502 Malmö, Sweden. ²Department of Geriatrics, Skåne University Hospital, Malmö, Sweden. ${ }^{3}$ Department of Clinical Sciences Malmö, Lund University, Malmö, Sweden. ${ }^{4}$ Department of Nephrology, Skåne University Hospital, Malmö, Sweden. ${ }^{5}$ Jan Waldenströms gata 15, plan 5, 20502 Malmö, Sweden.

Received: 18 July 2017 Accepted: 16 November 2017

Published online: 04 December 2017

\section{References}

1. Christensson A, Elmstahl S. Estimation of the age-dependent decline of glomerular filtration rate from formulas based on creatinine and cystatin C in the general elderly population. Nephron Clin Pract. 2011;117(1):C40-50.

2. Corsonello A, Pedone C, Bandinelli S, Ferrucci L, Antonelli Incalzi R. Agreement between chronic kidney disease epidemiological collaboration and Berlin initiative study equations for estimating glomerular filtration rate in older people: the Invecchiare in Chianti (aging in Chianti region) study. Geriatr Gerontol Int. 2017;17(10):1559-67. doi:10.1111/ggi.12932.

3. Karsch-Volk M, Schmid E, Wagenpfeil S, Linde K, Heemann U, Schneider A. Kidney function and clinical recommendations of drug dose adjustment in geriatric patients. BMC Geriatr. 2013;13:92.

4. Lujambio I, Sottolano M, Luzardo L: Estimation of Glomerular filtration rate based on serum Cystatin C versus Creatinine in a Uruguayan population. Int J Nephrol. 2014;2014:837106. 
5. Modig S, Lannering C, Ostgren CJ, Molstad S, Midlov P. The assessment of renal function in relation to the use of drugs in elderly in nursing homes; a cohort study. BMC Geriatr. 2011;11:1.

6. Peralta CA, Shlipak MG, Judd S, Cushman M, McClellan W, Zakai NA, Safford MM, Zhang X, Muntner P, Warnock D. Detection of chronic kidney disease with creatinine, cystatin $C$, and urine albumin-to-creatinine ratio and association with progression to end-stage renal disease and mortality. JAMA. 2011;305(15):1545-52.

7. Tsai CW, Grams ME, Inker LA, Coresh J, Selvin E. Cystatin C- and creatininebased estimated glomerular filtration rate, vascular disease, and mortality in persons with diabetes in the U.S. Diabetes Care. 2014;37(4):1002-8.

8. Bjork J, Grubb A, Larsson A, Hansson LO, Flodin M, Sterner G, Lindstrom V, Nyman U. Accuracy of GFR estimating equations combining standardized cystatin C and creatinine assays: a cross-sectional study in Sweden. Clin Chem Lab Med. 2015:53(3):403-14.

9. Fan L, Levey AS, Gudnason V, Eiriksdottir G, Andresdottir MB, Gudmundsdottir $\mathrm{H}$, Indridason OS, Palsson R, Mitchell G, Inker LA. Comparing GFR estimating equations using Cystatin $C$ and Creatinine in elderly individuals. J Am Soc Nephrol. 2015;26(8):1982-9.

10. Inker LA, Schmid CH, Tighiouart H, Eckfeldt JH, Feldman HI, Greene T, Kusek JW, Manzi J, Van Lente F, Zhang YL, et al. Estimating glomerular filtration rate from serum creatinine and cystatin C. N Engl J Med. 2012;367(1):20-9.

11. Christensson A, Grubb A, Molvin J, Holm H, Gransbo K, Tasevska-Dinevska G, Bachus E, Jujic A, Magnusson M. The shrunken pore syndrome is associated with declined right ventricular systolic function in a heart failure population - the HARVEST study. Scand J Clin Lab Invest. 2016;76(7):568-74.

12. Dardashti A, Nozohoor S, Grubb A, Bjursten H. Shrunken pore syndrome is associated with a sharp rise in mortality in patients undergoing elective coronary artery bypass grafting. Scand J Clin Lab Invest. 2016;76(1):74-81.

13. Purde MT, Nock S, Risch L, Medina Escobar P, Grebhardt C, Nydegger UE, Stanga Z, Risch M. Ratio of cystatin C and creatinine-based estimates of the glomerular filtration rate predicts mortality in healthy seniors independent of kidney function. Scand J Clin Lab Invest. 2016;76(4):341-3.

14. Macdonald J, Marcora S, Jibani M, Roberts G, Kumwenda M, Glover R, Barron J, Lemmey A. GFR estimation using cystatin C is not independent of body composition. Am J Kidney Dis. 2006;48(5):712-9.

15. Muntner P, Winston J, Uribarri J, Mann D, Fox CS. Overweight, obesity, and elevated serum cystatin C levels in adults in the United States. Am J Med. 2008;121(4):341-8

16. Ichihara $K$, Saito $K$, Itoh $Y$. Sources of variation and reference intervals for serum cystatin $C$ in a healthy Japanese adult population. Clin Chem Lab Med. 2007;45(9):1232-6.

17. Wei L, Ye X, Pei X, Wu J, Zhao W. Reference intervals for serum cystatin C and factors influencing cystatin $C$ levels other than renal function in the elderly. PLoS One. 2014;9(1):e86066.

18. Wasen E, Isoaho R, Mattila K, Vahlberg T, Kivela SL, Irjala K. Serum cystatin C in the aged: relationships with health status. Am J Kidney Dis. 2003;42(1):36-43.

19. Naour N, Fellahi S, Renucci JF, Poitou C, Rouault C, Basdevant A, Dutour A, Alessi MC, Bastard JP, Clement K, et al. Potential contribution of adipose tissue to elevated serum cystatin $C$ in human obesity. Obesity (Silver Spring). 2009;17(12):2121-6.

20. Vinge $E$, Lindergard B, Nilsson-Ehle $P$, Grubb A. Relationships among serum cystatin C, serum creatinine, lean tissue mass and glomerular filtration rate in healthy adults. Scand J Clin Lab Invest. 1999;59(8):587-92.

21. Knight EL, Verhave JC, Spiegelman D, Hillege HL, de Zeeuw D, Curhan GC, de Jong PE. Factors influencing serum cystatin $C$ levels other than renal function and the impact on renal function measurement. Kidney Int. 2004; 65(4):1416-21

22. Liu X, Foster MC, Tighiouart H, Anderson AH, Beck GJ, Contreras G, Coresh J, Eckfeldt JH, Feldman $\mathrm{HI}$, Greene T, et al. Non-GFR determinants of lowmolecular-weight serum protein filtration markers in CKD. Am J Kidney Dis. 2016:68(6):892-900.

23. Stevens LA, Schmid CH, Greene T, Li L, Beck GJ, Joffe MM, Froissart M, Kusek JW, Zhang YL, Coresh J, et al. Factors other than glomerular filtration rate affect serum cystatin C levels. Kidney Int. 2009;75(6):652-60.

24. Salive ME, Jones CA, Guralnik JM, Agodoa LY, Pahor M, Wallace RB. Serum creatinine levels in older adults: relationship with health status and medications. Age Ageing. 1995;24(2):142-50

25. Jayagopal V, Keevil BG, Atkin SL, Jennings PE, Kilpatrick ES. Paradoxical changes in cystatin $\mathrm{C}$ and serum creatinine in patients with hypo- and hyperthyroidism. Clin Chem. 2003:49(4):680-1.
26. Manetti L, Pardini E, Genovesi M, Campomori A, Grasso L, Morselli LL, Lupi I, Pellegrini G, Bartalena L, Bogazzi F, et al. Thyroid function differently affects serum cystatin $C$ and creatinine concentrations. J Endocrinol Investig. 2005:28(4):346-9.

27. Shirota T, Shinoda T, Yamada T, Aizawa T. Alteration of renal function in hyperthyroidism: increased tubular secretion of creatinine and decreased distal tubule delivery of chloride. Metab Clin Exp. 1992;41(4):402-5.

28. Wiesli P, Schwegler B, Spinas GA, Schmid C. Serum cystatin C is sensitive to small changes in thyroid function. Clin Chim Acta. 2003;338(1-2):87-90.

29. Bokenkamp A, van Wijk JA, Lentze MJ, Stoffel-Wagner B. Effect of corticosteroid therapy on serum cystatin $\mathrm{C}$ and beta2-microglobulin concentrations. Clin Chem. 2002;48(7):1123-6.

30. Risch L, Herklotz R, Blumberg A, Huber AR. Effects of glucocorticoid immunosuppression on serum cystatin $C$ concentrations in renal transplant patients. Clin Chem. 2001:47(11):2055-9.

31. Silva MV, Moscoso Solorzano G, Nishida SK, Kirsztajn GM. Are serum cystatin C levels influenced by steroid doses in lupus nephritis patients? J Bras Nefrol. 2011;33(3):306-12.

32. Cimerman N, Brguljan PM, Krasovec M, Suskovic S, Kos J. Serum cystatin C, a potent inhibitor of cysteine proteinases, is elevated in asthmatic patients. Clin Chim Acta. 2000:300(1-2):83-95.

33. Grubb A, Bjork J, Nyman U, Pollak J, Bengzon J, Ostner G, Lindstrom V. Cystatin C, a marker for successful aging and glomerular filtration rate, is not influenced by inflammation. Scand J Clin Lab Invest. 2011;71(2):145-9.

34. Vupputuri S, Fox CS, Coresh J, Woodward M, Muntner P. Differential estimation of CKD using creatinine- versus cystatin C-based estimating equations by category of body mass index. Am J Kidney Dis. 2009;53(6):993-1001.

35. Yamada Y, Noborisaka Y, Ishizaki M, Yamazaki M, Honda R, Yokoyama H, Kakuma T. Different association of cigarette smoking with GFR estimated from serum creatinine and that from serum cystatin $C$ in the general population. Clin Exp Nephrol. 2015;19(4):669-77.

36. Rule AD, Bailey KR, Lieske JC, Peyser PA, Turner ST. Estimating the glomerular filtration rate from serum creatinine is better than from cystatin $\mathrm{C}$ for evaluating risk factors associated with chronic kidney disease. Kidney Int. 2013;83(6):1169-76

37. Kimmel M, Braun N, Alscher MD. Influence of thyroid function on different kidney function tests. Kidney Blood Press Res. 2012;35(1):9-17.

38. Schei J, Stefansson VT, Mathisen UD, Eriksen BO, Solbu MD, Jenssen TG, Melsom T. Residual associations of inflammatory markers with eGFR after accounting for measured GFR in a community-based cohort without CKD. Clin J Am Soc Nephrol. 2016;11(2):280-6.

39. Alshaer IM, Kilbride HS, Stevens PE, Eaglestone G, Knight S, Carter JL, Delaney MP, Farmer CK, Irving J, O'Riordan SE, et al. External validation of the Berlin equations for estimation of GFR in the elderly. Am J Kidney Dis. 2014:63(5):862-5.

40. Kilbride HS, Stevens PE, Eaglestone G, Knight S, Carter JL, Delaney MP, Farmer CK, Irving J, O'Riordan SE, Dalton RN, et al. Accuracy of the MDRD (modification of diet in renal disease) study and CKD-EPI (CKD epidemiology collaboration) equations for estimation of GFR in the elderly. Am J Kidney Dis. 2013;61(1):57-66.

41. Fan L, Inker LA, Rossert J, Froissart M, Rossing P, Mauer M, Levey AS. Glomerular filtration rate estimation using cystatin $C$ alone or combined with creatinine as a confirmatory test. Nephrol Dial Transplant. 2014:29(6):1195-203.

42. Werner K, Pihlsgard M, Elmstahl S, Legrand H, Nyman U, Christensson A. Combining Cystatin $\mathrm{C}$ and Creatinine yields a reliable Glomerular filtration rate estimation in older adults in contrast to beta-trace protein and beta2microglobulin. Nephron. 2017;

43. Stevens LA, Zhang Y, Schmid CH. Evaluating the performance of equations for estimating glomerular filtration rate. J Nephrol. 2008;21(6):797-807.

44. Galteau MM, Guyon M, Gueguen R, Siest G. Determination of serum cystatin C: biological variation and reference values. Clin Chem Lab Med. 2001;39(9):850-7.

45. Burgess E, Blair A, Krichman K, Cutler RE. Inhibition of renal creatinine secretion by cimetidine in humans. Ren Physiol. 1982;5(1):27-30.

46. Delanaye P, Cavalier E, Pottel H: Serum Creatinine: not so simple! Nephron. 2017; 136(4):302-8. doi:10.1159/000469669.

47. Delanaye P, Mariat C, Cavalier E, Maillard N, Krzesinski JM, White CA Trimethoprim, creatinine and creatinine-based equations. Nephron Clin Pract. 2011;119(3):c187-93. discussion c193-184

48. Chew-Harris JS, Florkowski CM, George PM, Elmslie JL, Endre ZH. The relative effects of fat versus muscle mass on cystatin $C$ and estimates of renal function in healthy young men. Ann Clin Biochem. 2013;50(Pt 1):39-46. 
49. Grubb A, Lindstrom V, Jonsson M, Back SE, Ahlund T, Rippe B, Christensson A. Reduction in glomerular pore size is not restricted to pregnant women Evidence for a new syndrome: 'shrunken pore syndrome'. Scand I Clin Lab Invest. 2015;75(4):333-40.

50. Purde MT, Nock S, Risch L, Medina Escobar P, Grebhardt C, Nydegger UE, Stanga Z, Risch M. The cystatin C/creatinine ratio, a marker of glomerular filtration quality: associated factors, reference intervals, and prediction of morbidity and mortality in healthy seniors. Transl Res. 2016;169:80-90. e81-82

51. Luders F, Meyborg M, Malyar N, Reinecke H. The Preinterventional CystatinCreatinine-ratio: a prognostic marker for contrast medium-induced acute kidney injury and long-term all-cause mortality. Nephron. 2015;131(1):59-65.

Submit your next manuscript to BioMed Central and we will help you at every step:

- We accept pre-submission inquiries

- Our selector tool helps you to find the most relevant journal

- We provide round the clock customer support

- Convenient online submission

- Thorough peer review

- Inclusion in PubMed and all major indexing services

- Maximum visibility for your research

Submit your manuscript at www.biomedcentral.com/submit
Biomed Central 